\title{
Interfaces entre o processo de legitimação do grupo escolar como instituição de saber e a ressignificação do lugar simbólico de Ouro Preto como cidade monumento*
}

\section{Interfaces between the legitimation process of a primary school as an institution of knowledge and the resignification of the symbolic place of Ouro Preto as a historical city}

JULIANA GORETTI APARECIDA BRAGA VIEGA**

Faculdade de Educação Universidade Federal de Minas Gerais Belo Horizonte (MG)

Brasil

ANA MARIA DE OLIVEIRA GALVÃO***

Faculdade de Educação Universidade Federal de Minas Gerais Belo Horizonte (MG)

Brasil

\footnotetext{
* Artigo recebido em: 16/01/2013. Aprovado em: 24/09/2013.

** Contato: julianabragaviega@yahoo.com.br.

*** Contato: anamgalvao@uol.com.br.
} 
RESUMO O objetivo deste artigo é discutir como a construção de uma imagem de lugar de memória preservada para Ouro Preto, Minas Gerais, influiu no processo de legitimação do Grupo Escolar D. Pedro II, criado naquela cidade. O período investigado foi de 1900 a 1920, e as fontes analisadas foram: relatórios, ofícios, listas, atas de exames dos(as) alunos(as), a legislação estadual, anais da Câmara dos Deputados mineira, atas da Câmara de Vereadores de Ouro Preto, jornais, dados estatísticos e duas obras sobre a cidade. Fundamentamo-nos, principalmente, nas noções de representação, de Roger Chartier, e de produção de lugar, de Michel de Certeau. Nossas análises nos permitiram concluir que o Grupo Escolar não nasceu legitimado. A construção de sua importância foi gradativa e influenciada pela produção de um sentido histórico para Ouro Preto. Parte dos agentes políticos municipais resistiu à criação do Grupo, talvez motivada pela perda do status de capital de Minas pela cidade e por seus elos com o regime imperial. Tais vínculos têm como uma de suas expressões o nome da escola.

Palavras-chave grupo escolar, Ouro Preto, representação

ABSTRACT The article aims to discuss how the construction of an image of preserved memory place for the city of Ouro Preto, Minas Gerais, has influenced the legitimation process of the Primary School D. Pedro II, built in the city. It was investigated the period between 1900 and 1920, and the analyzed sources were: reports, official letters, lists, minutes of the students' exams, the state legislation, Minas Gerais Chamber of Deputies annals, Ouro Preto City Council minutes, newspapers, statistics. This research was especially based on Roger Chartier's notions of representation and Michel de Certeau's notions of production of place. The analysis led to the conclusion that the focused Primary School was not originated as a legitimized institution. The construction of its importance was gradual and influenced by the production of a historical sense to Ouro Preto. Part of the municipal politicians resisted the creation of the School, perhaps motivated by the loss of the status of capital city of Minas and its connections with the imperial regime. Such bonds have as one of its expressions the school's name.

Keywords primary school, Ouro Preto, representation

\section{Introdução}

Por meio de que modos o grupo escolar tornou-se uma instituição legítima de saber? Que fatores interferiram na produção de um lugar ou de representações para ele? Durante os anos iniciais de edificação do regime republicano, a necessidade de incorporar a população à nova ordem que 
se pretendia instaurar e de preparar e integrar os trabalhadores livres ao mercado de trabalho tornou-se cada vez mais intensa. Para construir uma nação republicana era preciso forjar uma identidade coletiva. A geração intelectual da Primeira República (1889-1930) se mobilizou com afinco para constituí-la. Nesse cenário, a educação assumiu um lugar muito importante. A construção de uma escola que contribuísse para a formação de uma sociedade afinada com as ideias de progresso e modernidade e para a homogeneização social tornou-se uma condição essencial para o pleno desenvolvimento da República. É nesse contexto que os grupos escolares foram constituídos. A criação das novas instituições de ensino começou, no Brasil, a partir de 1893, quando leis com aquele fim foram promulgadas em São Paulo e no Rio de Janeiro. A primeira instalação de fato ocorreu em 1894, no estado de São Paulo. Embora tenham surgido, a princípio, em apenas uma região, as discussões a respeito da implantação dos grupos escolares já estavam sendo realizadas em outras localidades do Brasil. Durante as duas primeiras décadas do século XX, os grupos foram fundados, gradualmente, em outros estados brasileiros como: Rio de Janeiro (1897); Maranhão e Paraná (1903); Minas Gerais (1906); Bahia, Rio Grande do Norte, Espírito Santo e Santa Catarina (1908); Mato Grosso (1910); Sergipe (1911); Paraíba (1916) e Piauí (1922). ${ }^{1}$

Os grupos escolares foram implantados como ideal de escola pública e caracterizados por um conjunto de inovações pedagógicas como a seriação e distribuição dos(as) alunos(as) em classes, por graus de conhecimento, no sentido de se obter turmas o mais homogêneas possíveis. A constituição legal do grupo escolar, reforçada por discursos de agentes políticos e da própria historiografia, dá a entender que ele foi criado como uma escola de verdade, em contraponto às escolas isoladas, para as quais foi fabricado um lugar de decadência, de desorganização, de irracionalidade. ${ }^{2}$ Mas, será que o grupo escolar nasceu como uma instituição, de fato, reconhecida, legítima?

Para problematizar essa questão, apresentamos, por meio deste artigo, parte dos resultados de um trabalho cujo principal objetivo foi descrever e analisar por meio de que modos se configurou o processo de constituição de uma representação de instituição legítima de saber para o grupo escolar.

1 Sobre a implantação dos grupos escolares em diferentes regiões do país, verificar a obra a seguir: VIDAL, Diana Gonçalves (org.). Grupos escolares: cultura escolar primária e escolarização da infância no Brasil (1893-1971). Campinas: Mercado de Letras, 2006.

2 O termo escola isolada - bem como as expressões escola singular, cadeira de instrução primária, cadeira isolada e cadeira singular - foi cunhado para conferir novas designações para as escolas de primeiras letras existentes durante o regime imperial, no Brasil. Elas eram responsáveis pela transmissão dos saberes elementares - ler, escrever e contar - para meninos e meninas. Seu público alvo foi, em especial, a população pobre, negra e mestiça que, segundo as autoridades governamentais da época, precisava ser civilizada, como pode ser verificado em: VEIGA, Cynthia Greive. História da educação. São Paulo: Ática, 2007. O termo escola isolada surgiu em São Paulo, a partir da Lei n. 88, de 1892, com a finalidade de diferenciar as instituições que nomeava dos grupos escolares. A esse respeito, é digno de nota o seguinte trabalho: ALVES, Silvane Rodrigues Leite. A instrução pública em Indaiatuba (1854-1930): contribuição para a história da educação brasileira. Campinas: Universidade Estadual de Campinas, 2007 (Educação, Dissertação de mestrado). 
Enfocamos, para tanto, o caso do Grupo Escolar D. Pedro II, situado em Ouro Preto, Minas Gerais. ${ }^{3}$ O período analisado refere-se aos anos de 1900 a 1920. A principal constatação construída ao longo de nossas análises foi a de que o grupo escolar não foi criado como uma instituição reconhecida, legítima. Tal legitimidade precisou ser fabricada, forjada, produzida. Neste artigo, pretendemos discutir como as mudanças pelas quais Ouro Preto passou nos anos iniciais do século XX influenciaram as discussões iniciais acerca da implantação do Grupo Escolar D. Pedro II naquela cidade e como tais discussões relacionam-se aos debates a respeito da criação dos grupos realizados na esfera estadual. Essas questões serão abordadas na primeira parte deste trabalho. Na segunda parte, analisaremos o nome conferido à escola como um dos indícios dos vínculos existentes entre a constituição da legitimação do Grupo Escolar e a história de Ouro Preto. Capital de Minas Gerais até fins do século XIX, Ouro Preto submergiu, durante os primeiros anos do século XX, em uma situação de crise acarretada pela transferência da sede administrativa do estado para a recém criada Belo Horizonte considerada, naquela ocasião, moderna. Para conferir, novamente, destaque a Ouro Preto foi-se, gradualmente, constituindo-a como um lugar de memória preservada, como explicam Rodrigo Meniconi e Caion Natal. ${ }^{4}$

O estudo sobre a legitimação do grupo escolar, em Ouro Preto, Minas Gerais, entre os anos de 1900 e 1920, se insere em um quadro mais geral de transformações pelas quais a historiografia passou durante todo o século XX. Para a problematização de nosso objeto, valemo-nos das formulações de Roger Chartier sobre o conceito de representação e das de Michel de Certeau acerca das ideias de discurso, discursividade reguladora e produção de lugar. ${ }^{5}$

Para compreender como foi engendrado um lugar legítimo para o Grupo Escolar D. Pedro II produzimos dados com base nas análises das seguintes fontes: legislação escolar estadual; termos de visita e relatórios de inspeção técnica; jornais da época; relatórios de diretores do Grupo Escolar de Ouro Preto; ofícios emitidos pela Secretaria do Interior e Justiça para as escolas de Ouro Preto; ofícios enviados por funcionários das escolas primárias da antiga capital de Minas para a Secretaria do Interior; listas contendo inventários sobre as escolas primárias, produzidas por elas próprias; listas de materiais recebidos pelas cadeiras isoladas e pelo Grupo Escolar; atas de exames realizados nas escolas; anais da Câmara dos Deputados de

3 A pesquisa a qual referimo-nos é: VIEGA, Juliana Goretti Aparecida Braga. O processo de legitimação do grupo escolar como instituição de saber (Ouro Preto, Minas Gerais, 1900-1920). Belo Horizonte: Universidade Federal de Minas Gerais, 2012 (Educação, Dissertação de mestrado).

4 MENICONI, Rodrigo Otávio de Marco. A construção de uma cidade-monumento: o caso de Ouro Preto. Belo Horizonte: Universidade Federal de Minas Gerais, 1999 (Arquitetura, Dissertação de mestrado). NATAL, Caion Meneguello. Ouro Preto: a construção de uma cidade histórica (1891-1933). Campinas: Universidade Estadual de Campinas, 2007 (História, Dissertação de mestrado).

5 Ver: CHARTIER, Roger. A história cultural: entre práticas e representações. Lisboa: Difel, 1990; CERTEAU, Michel de. A invenção do cotidiano: 1. Artes de fazer. 2 ed. Petrópolis: Vozes, 1996; CERTEAU, Michel de. A escrita da história. 2 ed. Rio de Janeiro: Forense Universitária, 2010. 
Minas Gerais; registros das atas da Câmara dos Vereadores de Ouro Preto; e outras fontes a respeito da antiga capital de Minas Gerais. Todas as fontes investigadas estão localizadas nos acervos do Arquivo Público Mineiro (APM), mais precisamente, do fundo da Secretaria do Interior e Justiça (SI); do Arquivo Público Municipal de Ouro Preto (APMOP); da Hemeroteca Pública de Belo Horizonte; da Casa do Pilar de Ouro Preto; e, da base de dados do Instituto Brasileiro de Geografia e Estatística (IBGE).

\title{
As primeiras discussões sobre a criação do grupo escolar em Ouro Preto: anseios de "engrandecer a instrucção" e possíveis re- sistências a um dos símbolos da República
}

\begin{abstract}
Pede a palavra o Sr. Dr. João Velloso e diz que o motivo que o levou a requerer a presente sessão é tratar-se de engrandecer a instrucção. Ouro Preto não pode, diz o orador, deixar de applaudir, embora com seo fraco concurso, a Idéa do governo na creação de grupos escolares. ${ }^{6}$
\end{abstract}

Por que motivos desejou-se instalar um grupo escolar em Ouro Preto? Que lugar foi conferido ao grupo escolar antes mesmo que ele fosse instalado? Que relações podem ser estabelecidas entre aquele lugar e o momento histórico pelo qual Ouro Preto passava? E entre os debates ocorridos na esfera do Estado sobre a reinvenção da escola primária pública e as discussões realizadas em Ouro Preto sobre a implantação de um grupo escolar?

Em Minas Gerais, parecia haver um significativo anseio de transformar as condições educacionais, tornando-as compatíveis com os valores e interesses republicanos. Em um pronunciamento na Câmara dos Deputados do estado, no ano de 1905, o então deputado Xavier Rolim comentou a respeito das tentativas frustradas empreendidas pelo governo mineiro para modificar o quadro educacional de Minas:

No decurso de dez annos, isto é, de 1892 - 1902, o Congresso mineiro votou nada menos de oito leis referentes ao ensino primario e normal, a saber: Leis $n$. 41, de agosto de 1892, n. 77, de dezembro de 1893, n. 106, de julho de 1894, n. 201 , de setembro de 1896, n. 221, de setembro de 1897, n. 281, de setembro de 1899, n. 322, de setembro de 1901 e n. 342, de setembro de 1902. Mas, infelizmente, o resultado foi sempre negativo, sempre nullo! ${ }^{7}$

Ao analisar a segunda reforma mineira da instrução pública no período republicano, a de 1899, executada por meio da Lei n. 281, o então presidente

6 APMOP. Livro de Registro de Atas das Sessões da Câmara Municipal de Ouro Preto, Livro 2, 1906-1912. N. de Registro: 01118. Acta da $2^{a}$ Sessão extraordinária em 20 de Abril de 1907, p.68.

7 APM. Congresso Mineiro. Annaes da Camara dos Deputados. Terceira Sessão da Quarta Legislatura do ano de 1905. 58 Sessão Ordinaria, aos 12 de Setembro de 1905, p.559. Continuação da segunda discussão referente 
do Estado, Francisco Silviano Brandão, ${ }^{8}$ enfatizou que medidas importantes como a efetivação da obrigatoriedade do ensino, a supressão do cargo de professor provisório, a distribuição mais igualitária das cadeiras públicas de ensino primário pelo estado, a criação da inspeção escolar extraordinária e a destinação de uma parte do orçamento estadual para a compra de mobília e materiais para as escolas primárias, haviam sido ordenadas por meio da referida lei. Isso, na perspectiva do mencionado presidente, simplificaria e tornaria o ensino mais uniforme, prático e vantajoso.

No entanto, como expôs o deputado Xavier Rolim em seu pronunciamento já citado, os resultados esperados com a promulgação dessa e de outras leis parecem não terem sido alcançados. Muitas críticas eram feitas ao sistema educacional primário mineiro por autoridades políticas, nos primeiros anos do século XX. Em 1901, por exemplo, ao discutir um projeto de lei a respeito da educação, o deputado João Velloso censurou a organização do ensino, a qual foi classificada por ele como rudimentar e anárquica sendo, portanto, um claro indício do atraso em que o estado se encontrava. O deputado concluiu sua participação no debate fazendo a seguinte afirmação: "Urge transformar de modo completo esta lamentavel situação do ensino, mas a transformação não é obra de um dia. Há de ir operando-se lentamente pela adopção de uma cultura pedagogica racional nos institutos normaes e adaptação do actual magisterio primario". ${ }^{9}$

Ressalta-se, ao analisar as palavras proferidas pelo deputado Xavier Rolim, que a representação construída acerca do ensino primário mineiro em fins do século XIX e início do século XX era de precariedade e desorganização. As opiniões expressas pelo deputado parecem revelar um discurso que descredenciava a forma como estava organizado o ensino, isto é, em cadeiras isoladas, como a mais adequada para se produzir uma educação escolar condizente com os padrões almejados para a República. Como explica Michel de Certeau, ${ }^{10}$ os discursos são marcados pelos usos que suscitam e apresentam as marcas de atos ou processos de enunciação. Eles têm o poder de produzir efeitos e, associados a outros aspectos, de fabricar objetos. No caso dos discursos proferidos por políticos mineiros, como o deputado Xavier Rolim, sobre a educação primária mineira em fins do século XIX e início do século

ao projeto N. 119, a respeito da reforma do ensino primário e normal

8 APM. Congresso Mineiro. Annaes da Camara dos Deputados. Segunda Sessão da Terceira Legislatura do ano de 1900. Acta da sessão solemne de installação para a $2^{a}$ sessão da $3^{a}$ legislatura do Congresso do Estado de Minas Geraes, aos 18 dias do mez de junho de 1900. Fala do Presidente do Estado Francisco Silviano de Almeida Brandão.

9 APM. Congresso Mineiro. Annaes da Camara dos Deputados. Terceira Sessão da Terceira Legislatura do ano de 1901. $42^{a}$ Sessão Ordinaria, aos 12 de Agosto de 1901, p.235. $3^{a}$ Discussão do Projecto N. 102. Fala do Deputado João Velloso.

10 CERTEAU, Michel de. A escrita da história. Rio de Janeiro: Forense, 1982. 
XX, nota-se uma possível produção de um sistema de ensino primário que, apesar das reformas sofridas durante anos, não correspondia às expectativas das autoridades.

A mesma produção de um sistema de ensino deficiente que precisava ser completamente reformulado também pode ser observada no discurso proferido dois anos depois, pelo próprio Presidente do Estado, Francisco Antonio de Salles:

Parece que o erro tem consistido em querer-se manter e aproveitar tudo quanto está feito, imprimindo nova feição aos moldes antigos e defeituosos. A decadencia do ensino publico é visivel. Ha falta de predios proprios onde funccionem as escolas, em condições hygienicas, providos de mobilia e material escolar conveniente. À maior parte dos professores falta o preparo necessario, a educação pedagogica, o estimulo, e, emfim, a inspecção do ensino. A falta de frequencia de alumnos que se nota nas escolas é a consequencia desse estado a que o ensino se acha reduzido. ${ }^{11}$

Na concepção de Francisco Salles havia a necessidade da realização de uma reforma completa e radical no ensino primário. Nesse sentido, para o Presidente, São Paulo constituía-se em um exemplo a ser seguido por ter implantado grupos escolares. Na ocasião da $14^{\mathrm{a}}$ sessão ordinária da Câmara dos Deputados, ocorrida em julho de 1903, um deputado identificado como Afrânio esclareceu aos colegas que tipo de ganhos o governo mineiro teria se decidisse adotar no estado os grupos escolares como forma prioritária de organização do ensino:

Imaginemos, sr. Presidente, que o Estado não tratasse de crear esse typo de estabelecimentos primarios, que as nossas escolas, excluídas as normaes, fossem unicamente as singulares: que difficuldade para que se fornecesse a cada uma dellas, isoladamente, todo o material didactico, que é um material custoso e complexo! Por consequencia, será muito mais econômico reunir toda a população escolar em um só edificio, onde haverá numeroso material didactico, tão necessario e essencial para o ensino, sobretudo da primeira infância, para o ensino primario. ${ }^{12}$ (Grifos nossos).

Michel de Certeau afirma que os discursos têm o poder de projetar, produzir e organizar lugares para seus objetos. A leitura e análise do trecho do pronunciamento feito pelo deputado Afrânio revela indícios de elementos do lugar produzido para as escolas isoladas na educação escolar mineira no início da República. Além da desorganização e do atraso, elas ainda eram

11 APM. Congresso Mineiro. Annaes da Camara dos Deputados. Primeira Sessão da Quarta Legislatura do ano de 1903. Acta da sessão solemne de installação para a $1^{2}$ sessão da $4^{a}$ legislatura do Congresso do Estado de Minas Geraes, aos 15 de junho de 1903, p.19. Fala do Presidente do Estado Francisco Antonio de Salles.

12 APM. Congresso Mineiro. Annaes da Camara dos Deputados. Primeira Sessão da Quarta Legislatura do ano de 1903. $14^{a}$ Sessão ordinária, aos 4 de julho de 1903, p.71. Discussão a respeito do projecto N. 1. Fala do Deputado Afrânio (não há registro de sobrenome). 
consideradas dispendiosas no que concernia a distribuição de materiais. Nesse caso, a criação dos grupos escolares é, na esfera do discurso do deputado, fabricada como mais vantajosa por supostamente beneficiar a distribuição de materiais para todas as escolas por permitir a reunião de um número considerável de crianças em um único prédio escolar. No entanto, o que se percebe é que as condições precárias em termos da materialidade de muitas escolas continuaram existindo após a instituição dos grupos escolares no estado de Minas Gerais. Eles próprios, inclusive o Grupo Escolar D. Pedro II, eram acometidos pela falta de materiais didáticos para o desenvolvimento do ensino.

Não obstante as proclamadas melhorias que poderiam ser geradas, no ensino primário, com a criação dos grupos, a questão financeira parecia constituir um importante entrave para a concretização da almejada reforma, como lamentou Francisco Salles, em sessão da Câmara, em 1904, quando era presidente do estado de Minas Gerais: "Uma reforma completa e feita em moldes convenientes encontra o maior obstaculo para sua execução prompta e immediata na escassez de recursos que póde dispor o Estado para esse ramo da administração publica". ${ }^{13}$

Após tentativas consideradas mal sucedidas, em 1906 a esperada reforma do ensino aconteceu, com a promulgação da Lei n. 439 de 28 de setembro, que reformava o ensino primário, normal e superior. A reforma foi realizada durante a gestão de João Pinheiro. Todavia, embora esse governador tenha exercido uma função importante para a sua concretização, outros agentes também participaram ativamente de sua execução, como Secretários do Interior e Justiça, intelectuais, inspetores de ensino e educadores(as). Como argumenta Irlen Gonçalves, a reforma pretendida e empreendida a partir de 1906, por João Pinheiro e sua equipe, foi uma obra de grandes proporções, na medida em que o objetivo era renovar por completo a instrução pública mineira. Por isso, nas palavras do autor, "essa reforma pode ser considerada a de maior vulto na história da escola destinada à parcela mais pobre da população mineira". ${ }^{14}$

O processo de reinvenção da escola, expresso inicialmente na Lei n. 439 e depois em outros dispositivos legais que a sucederam, cuja expressão máxima era o grupo escolar, envolvia a reelaboração de métodos e concepções de ensino, a contratação de professores(as) normalistas, a produção de um novo programa e de novos espaços para a escola

13 APM. Congresso Mineiro. Annaes da Camara dos Deputados. Segunda Sessão da Quarta Legislatura do ano de 1904. Acta da sessão solemne de installação para a $2^{2}$ sessão da $4^{a}$ legislatura do Congresso do Estado de Minas Geraes, aos 18 de junho de 1904, p.18. Fala do Presidente do Estado Francisco Antonio de Salles.

14 GONÇALVES, Irlen Antônio. Cultura escolar: práticas e produção dos grupos escolares em Minas Gerais (18911918). Belo Horizonte: Autêntica/FCH-FUMEC, 2006, p.78. 
primária, a redefinição dos tempos escolares. ${ }^{15}$ Por funcionar como uma discursividade reguladora, como diria Michel de Certeau, o intuito da nova lei, portanto, era instaurar novas práticas relativas à instrução pública, que deveriam ser executadas por todos os agentes envolvidos na organização do ensino primário.

Meses após a divulgação da reforma, o presidente João Pinheiro, em pronunciamento à Câmara dos Deputados, declarou que:

A refórma teve de ser completa e total quanto aos methodos de ensino, á disciplina escolar e á fiscalização severa do serviço, estando o Governo cuidando da questão de casas escolares apropriadas e do respectivo mobiliario, dentro dos restrictos recursos orçamentarios. (...) Entretanto, é cedo ainda para nos julgarmos senhores de uma victoria definitiva: a refórma tem que lutar com os habitos maus e inveterados, com um professorado que não estava sufficientemente preparado para a pratica dos novos methodos e por isso será preciso ainda, e por tempos, uma acção intensa e mantida, premunidos todos contra os desanimos vis, de que as infelizes retrogradações são filhas. ${ }^{16}$

O que as palavras de João Pinheiro sinalizam? Ao que parece elas reforçam o lugar destinado aos grupos escolares e às escolas isoladas no cenário educacional mineiro: os primeiros sendo representados como a organização de ensino mais eficiente, enquanto as últimas simbolizavam o lugar dos maus hábitos, daquilo que precisava ser combatido.

As discussões a respeito do possível estabelecimento de um grupo escolar em Ouro Preto, ao que tudo indica, começaram a ser realizadas na Câmara dos Vereadores do município em abril de 1907, cerca de sete meses após a promulgação da Lei n. 439 e antes de João Pinheiro elaborar suas considerações sobre a reforma do ensino na Câmara dos Deputados. Nesse momento, o então deputado João Baptista Ferreira Velloso, que já havia participado dos debates sobre a reforma da instrução primária na Câmara dos Deputados, e alguns dos vereadores ouropretanos levaram à Câmara Municipal a proposta de criação de, pelo menos, um grupo escolar em Ouro Preto, como se pode verificar a seguir:

No intuito de promover-se a creação, pelo menos, de um grupo escolar, nesta cidade, pretendem os vereadores abaixo assignados, submetter á esclarecida consideração da Camara Municipal, uma indicação que proporcione a installação de um desses institutos de ensino, que de perto consultam os mais elevados

15 FARIA FILHO, Luciano Mendes de. Dos pardieiros aos palácios: cultura escolar e urbana em Belo Horizonte na Primeira República. São Paulo: Universidade de São Paulo, 1996 (Educação, Tese de doutorado); SOUZA, Rosa de Fátima. Templos de civilização: a implantação da Escola Primária graduada no Estado de São Paulo (18901910). São Paulo: UNESP, 1998; VIDAL, Diana Gonçalves (org.). Grupos escolares.

16 APM. Congresso Mineiro. Annaes da Camara dos Deputados. Primeira Sessão da Quinta Legislatura do ano de 1907. Acta da sessão solemne de installação para a $1^{a}$ sessão da $5^{a}$ legislatura do Congresso do Estado de Minas Geraes, aos 15 de junho de 1907, p.13. Fala do Presidente do Estado João Pinheiro da Silva. 
interesses do povo, rogam, pois, a V. Exa ${ }^{\mathrm{a}}$. se digne convocar a Camara Municipal para uma sessão extraordinária, para o mencionado fim e E. Deferimento. ${ }^{17}$

Na perspectiva do parlamentar e dos vereadores que o apoiavam, Ouro Preto não podia deixar de prestigiar a reforma intentada pelo governo mineiro, afinal, segundo eles, a implantação de grupos escolares estava de acordo com os anseios do povo. Embora houvesse o aparente interesse de uma parte da classe política no processo de implantação da nova organização da instrução em Ouro Preto e isso pudesse contribuir para conferir certa importância ao grupo escolar, obstáculos entravavam a concretização da proposta. Assim como o restante do estado, Ouro Preto parecia enfrentar dificuldades financeiras. Wenceslau Gonçalves Neto, em seu estudo a respeito da instrução primária pública em Ouro Preto e em Uberabinha, esclarece que a Câmara Municipal da antiga capital de Minas, em fins do século XIX, alegava falta de recursos para investir na criação de cadeiras públicas de ensino. O autor ressalta que os vereadores, em virtude de uma suposta preocupação com as finanças do município, chegaram a aprovar uma lei que transferia para os distritos de Ouro Preto a responsabilidade com o financiamento da criação de escolas singulares municipais, fato que parece ter gerado protestos entre os habitantes dos distritos. ${ }^{18} \mathrm{~A}$ falta de recursos parecia afetar não apenas a criação de escolas primárias. José Murilo de Carvalho, ao analisar a história da Escola de Minas de Ouro Preto, ressalta que a escassez de recursos financeiros daquela localidade foi uma das dificuldades encontradas para a implantação e consolidação da instituição. ${ }^{19}$

Em relação aos entraves financeiros para a criação de um grupo escolar na localidade, parte de um pronunciamento do deputado João Velloso, registrado em uma das atas das reuniões da Câmara, oferece pistas a respeito da situação: "sabe-se que não ha predios que sirvam, por falta de distribuição de luz, ar, etc. Não desconhece as condições precaríssimas da Camara, mas tratando-se da instrucção, não pode deixar de exigir que se faça um pequeno sacrifício". ${ }^{20}$ Como forma de impedir que a suposta situação financeira precária pela qual a Câmara passava impossibilitasse a criação do grupo, o deputado João Velloso propôs a adaptação de um prédio, ao invés da construção de um, para que a nova instituição fosse instalada e indicou o Presidente da Câmara para conversar com o governo

17 APMOP. Livro de Registro de Atas das Sessões da Câmara Municipal de Ouro Preto, Livro 2, 1906-1912. N. de Registro: 01118. Acta da $2^{a}$ Sessão extraordinária, em 20 de Abril de 1907, p.68.

18 GONÇALVES NETO, Wenceslau. Capital e interior: manifestações em prol da instrução pública em Ouro Preto e Uberabinha (MG) nos anos iniciais da República Brasileira. Educação em Revista, Belo Horizonte, v.26, n.2, p.189208, 2010

19 CARVALHO, José Murilo de. A escola de Minas de Ouro Preto: o peso a glória. Rio de Janeiro: Centro Edelstein de Pesquisas Sociais, 2010

20 APMOP. Livro de Registro de Atas das Sessões da Câmara Municipal de Ouro Preto, Livro 2, 1906-1912. N. de Registro: 01118. Acta da $2^{a}$ Sessão extraordinária em 20 de Abril de 1907, p.69. 
do estado a esse respeito. É interessante ressaltar o empenho do deputado João Velloso no processo de constituição de um grupo escolar em Ouro Preto, sua terra natal. Talvez, o deputado vislumbrasse naquela criação uma possibilidade de obter algum reconhecimento para sua carreira política e, ao mesmo tempo, mostrar que Ouro Preto também queria estar inserida na modernização do ensino primário. Entretanto, uma parte das autoridades políticas do município, aparentemente, não estava tão entusiasmada com a ideia. O Presidente da Câmara, por exemplo, recusou a indicação para conversar com o governo estadual, como havia proposto o deputado, alegando não poder comprometer a receita do município. O agente municipal acabou sendo alvo de críticas por parte do parlamentar, como é possível notar na citação abaixo:

O Sr. João Velloso diz que não o sorprehende a attitude do Sr. Presidente, porque aqui só trata-se de politicagem, e o governo, que cria grupos escolares, em toda parte, não o farci em Ouro Preto, porque a Camara, que é um pardieiro velho cheio de ratasanas, não o quer pedir, offerecendo algum auxilio. ${ }^{21}$

Além do entrave oriundo da questão financeira, havia, ainda, uma aparente resistência por parte das autoridades ouropretanas em efetivar a reforma do ensino primário engendrada pelo governo mineiro. Enquanto nos anais da Câmara dos Deputados havia uma intensa defesa do novo modelo escolar, em Ouro Preto, alguns vereadores, durante os debates sobre a possível fundação de um grupo no município, aparentemente não se mostravam convencidos dos possíveis benefícios que a criação da instituição poderia acarretar para a instrução primária pública da cidade. De todo modo, o fato de ter havido debates na Câmara Municipal com o intuito de discutir a possibilidade de Ouro Preto ter uma escola como o grupo escolar pode ter conferido, em alguma medida, visibilidade para a instituição, antes mesmo que ela fosse criada.

Talvez a possível falta de interesse inicial pela implantação do grupo, por parte dos agentes políticos ouropretanos, estivesse relacionada à ligação que foi estabelecida entre a antiga capital de Minas Gerais e o regime imperial. Durante o Império, Ouro Preto gozou de certo destaque no cenário nacional. Além de ser a sede administrativa de Minas Gerais ao longo de todo o período em que o Brasil constituía-se como uma monarquia, aquela localidade, assim como todas as vilas que eram capitais, foi elevada ao lugar de cidade por meio de um decreto imperial de 24 de fevereiro de 1823. ${ }^{22}$ Nessa mesma data, recebeu o título de "Imperial Cidade de Ouro

21 APMOP. Livro de Registro de Atas das Sessões da Câmara Municipal de Ouro Preto, Livro 2, 1906- 1912. N. de Registro: 01118. Acta da $2^{a}$ Sessão extraordinária em 20 de Abril de 1907, p.69.

22 CABRAL, Henrique Barbosa da Silva. Ouro Preto. Belo Horizonte: Imprensa Oficial, 1969. 
Preto", condição "que só deixou de ser invocada com a República". ${ }^{23}$ A concessão do dito título para Ouro Preto a tornou, na perspectiva de Caion Natal, representante dos preceitos monarquistas.

Deve-se acrescentar a esse quadro o fato de Ouro Preto ter participado, em certa medida, do processo denominado por José Murilo de Carvalho de "construção da ordem do Império". ${ }^{24} \mathrm{O}$ autor argumenta que muitos foram os fatores que possibilitaram a constituição de uma ordem para a monarquia brasileira. Como sinaliza em seu estudo, a homogeneidade em termos ideológico e de treinamento, aspecto que na opinião do autor contribuiria para dificultar a existência de conflitos no interior das elites e que auxiliaria na formação política daquele grupo; a herança da burocracia de Portugal, que sustentou a manutenção da unidade da ex-colônia; os cargos ocupados pelos membros da elite imperial; e, a educação, isto é, a criação de alguns estabelecimentos de ensino superior no Brasil, entre eles, a Escola de Farmácia, fundada em 1839, e a Escola de Minas, instalada em 1876, ambas em Ouro Preto, ${ }^{25}$ foram alguns dos fatores que se constituíram como fundamentais para garantir a unificação da elite imperial e para fabricar uma ordem para a monarquia brasileira.

Com a Proclamação da República, Ouro Preto, como será abordado posteriormente, perdeu prestígio significativamente, deixou de ser capital de Minas Gerais e entrou em um período de decadência. O fato de o grupo escolar ser considerado um dos principais símbolos do regime republicano, pode, num primeiro momento, ter contribuído para que os agentes políticos locais não se mobilizassem tão intensamente para executar a implantação de uma instituição como aquela na cidade. Em Mariana, cidade vizinha a Ouro Preto, uma situação contrária parecia ser observada. Lívia Vieira explica que, naquele município, houve uma arregimentação das autoridades que ocupavam os postos de poder político na cidade, nos anos iniciais do século XX, em torno da fundação do Grupo Escolar. ${ }^{26} \mathrm{~A}$ autora ressalta que tais agentes políticos estavam associados ao grupo republicano. Em relação a Ouro Preto, talvez, o grau de mobilização das autoridades da cidade estivesse relacionado não somente a uma discordância em relação aos princípios republicanos ou a uma possível insatisfação com o fim da Monarquia, mas à associação feita por elas entre a República e a mudança

23 ALMEIDA, Lúcia Machado de. Passeio a Ouro Preto. Belo Horizonte/São Paulo: Itatiaia/Editora da Universidade de São Paulo, 1980, p.40.

24 CARVALHO, José Murilo de. A construção da ordem: a elite política imperial. Brasília: Editora Universidade de Brasília, 1981. (Coleção Temas Brasileiros, v.4).

25 Eduardo Paiva, em pesquisa sobre o contexto mineiro após a mineração, concluiu que a modernização de Minas Gerais, em termos econômicos, solidificou-se por meio da formação educacional das elites, que se deu também nos estabelecimentos de ensino superior criados em Ouro Preto no século XIX. Consultar: PAIVA, Eduardo França. Minas depois da mineração [ou o século XIX mineiro]. In: GRINBERG, Keila; SALLES, Ricardo (orgs.). O Brasil Imperial - 1808-1831. v.1. Rio de Janeiro: Civilização Brasileira, 2009.

26 VIEIRA, Lívia Carolina. Das escolas isoladas ao grupo escolar: a instrução pública primária em Mariana, MG (18891915). São Carlos: Universidade Federal de São Carlos, 2011 (Educação, Dissertação de mestrado). 
da capital, que acarretou sérias consequências para vida e para o ordenamento de Ouro Preto.

Todavia, a despeito dos problemas iniciais, as discussões a respeito do assunto continuaram e, em 1908, o debate sobre a questão do prédio onde seria instalada a instituição caminhava para uma possível solução:

Art $1^{\circ}$ Fica o Presidente da Camara auctorisado a adquirir a casa situada na Rua do Bonfim a direita do edificio das Escolas D. Pedro $2^{\circ}$ para auxiliar o estabelecimento do Grupo Escolar de Ouro Preto; para o que entrará em accordo com quem de direito, na sucessão de Antonio Rodrigues do Nascimento, em relação ao preço, que será descontado do que essa sucessão deve á Fazenda Municipal. Art $2^{\circ}$. Da mesma forma procederá em relação á parte de terrenos que pertencem a viuva de Carlos Benedito. Art $3^{\circ}$ Feitas estas acquisições, o Presidente da Camara as entregará ao Governo do Estado, sem condições senão para o mencionado fim. Art $4^{\circ}$. Si o Presidente da Camara não chegar á accordo com os proprietários, procederá á desappropriação na forma da Lei. ${ }^{27}$

Não é possível afirmar com certeza se a casa que a Câmara dos Vereadores pretendia adquirir para auxiliar na instalação do Grupo foi comprada ou desapropriada para aquele fim. No entanto, a criação legal da instituição aconteceu em 1908. ${ }^{28}$ No início do ano seguinte, o Grupo começou a funcionar no edifício das escolas D. Pedro II, referido na citação anterior. Para tanto, as cadeiras de ensino primário que lá existiam foram suprimidas pelo Decreto n. 2.389, de 19 de janeiro de 1909. Embora o funcionamento da instituição tenha sido iniciado em janeiro, somente em 18 de abril de 1909 o Grupo Escolar foi instalado oficialmente em Ouro Preto. Ao que tudo indica, o início do funcionamento do Grupo em Ouro Preto pode ter sido relativamente agilizado em relação à sua criação legal.

Se, a princípio, a ideia da implantação da nova instituição pode não ter sido tão aclamada por uma parte da elite política do município, a possível fomentação de sua abertura pode significar que a implantação de um grupo escolar poderia ter sido encarada, em um segundo momento, como algo vantajoso para a cidade, algo que contribuiria para conferir-lhe algum destaque no cenário político estadual republicano. Afinal, a mudança da capital para Belo Horizonte e sua estreita relação com o antigo regime imperial deixaram Ouro Preto com uma imagem fragilizada nos primeiros anos da República.

27 APMOP. Livro de Registro de Atas das Sessões da Câmara Municipal de Ouro Preto, Livro 2, 1906- 1912. N. de Registro: 01118. Acta da $1^{a}$ Sessão extraordinária, em $1^{\circ}$ de Junho de 1908, p.100.

28 A criação se deu por meio do Decreto n. 2.296, de 17 de novembro de 1908. MINAS GERAIS. Decreto n. 2.296 de 17 de novembro de 1908. Crêa o grupo escolar da cidade de Ouro Preto. Imprensa Oficial, Belo Horizonte, 1908. 


\section{A escolha do nome da instituição: uma exaltação ao passado?}

Qual a importância que a escolha da denominação de uma instituição poderia ter para o local onde ela estava situada e para sua própria história? Seria a definição de um nome para o grupo escolar parte de uma estratégia mais ampla ou seria apenas uma decisão restrita à história da instituição? Criar uma escola da República para a República. Conforme Rosa Fátima de Souza, ${ }^{29}$ esse seria o projeto do governo republicano: construir, não apenas no sentido material, mas, sobretudo, simbólico, uma instituição escolar que se afinasse com os propósitos do novo regime. Portanto, todos os aspectos envolvidos nesse processo de construção deveriam fazer alusão à República, inclusive, o nome escolhido para as instituições. Ao analisar as denominações conferidas aos primeiros grupos escolares de Santa Catarina, Vera Silva constatou que às instituições "foram inscritos nomes de pessoas influentes no cenário político e eles foram inaugurados com grande pompa". ${ }^{30}$ Em outras palavras, a autora quer dizer que aos grupos foram dados nomes de figuras políticas importantes de Santa Catarina, cuja trajetória estava vinculada à República. Um deles, por exemplo, recebeu o nome de Grupo Escolar Vidal Ramos, homenageando o governador do estado na época, ano de 1913.

Em outras localidades, o grupo escolar recebeu o nome da cidade sede. Esse foi o caso da instituição de Mariana. Segundo Carvalho et al, ${ }^{31}$ naquele município, o Grupo, inaugurado em 1909, foi denominado de Grupo Escolar de Mariana. Porém, em 1914, seu nome mudou para Grupo Escolar Gomes Freire, em referência ao médico, professor da Escola de Farmácia e Presidente da Câmara de Mariana, Gomes Henrique Freire de Andrade. Rosa Fátima de Souza, investigando a história de alguns dos grupos escolares fundados em São Paulo, no período compreendido entre os anos de 1894 e 1910, concluiu que, por meio dos nomes que foram conferidos a eles, propagou-se a memória de importantes atores do cenário republicano paulista, como, por exemplo, Bernardino de Campos, Prudente de Morais, Gabriel Prestes.

Mas, e no que concerne ao Grupo Escolar de Ouro Preto? Não foram encontradas fontes que permitissem produzir dados sobre como ocorreu o processo de escolha do nome para a instituição. No entanto, o que foi possível averiguar é que ele recebeu a designação de Grupo Escolar D. Pedro II. Entretanto, o que motivou uma instituição, considerada símbolo do regime republicano, ter sido nomeada de D. Pedro II, nome do último

29 SOUZA, Rosa Fátima de. Templos de civilização.

30 SILVA, Vera Lúcia Gaspar da. Vitrines da República: os grupos escolares em Santa Catarina (1899-1930). In: VIDAL, Diana Gonçalves (org.). Grupos escolares, p.341-376, p.347.

31 CARVALHO, Rosana Areal de; MÁRQUES, Elisângela F.; FARIA, Vinícius Leal. Grupo escolar de Mariana: educação pública em Mariana no início do século XX. Revista HISTEDBR on line, Campinas, n.21, p.2-14, 2006. Disponível em: <http://www.histedbr.fae.unicamp.br/revis.html>. Acesso em: 20 nov. 2011. 
governante do Brasil Império? Primeiramente, é preciso mencionar que o Grupo Escolar de Ouro Preto foi instalado em um edifício, de propriedade do estado, que foi doado à cidade pelo ex-imperador D. Pedro II. ${ }^{32} \mathrm{Um}$ ato de 1908 conferiu a ela o nome de Grupo Escolar D. Pedro II. ${ }^{33}$ Contudo, essa denominação, talvez, não possa ser explicada apenas pelo fato de se ter decidido instalar a escola em um edifício que já possuía a nomenclatura de D. Pedro II. Embora essa seja uma das razões, provavelmente, não é a única. Levantamos a hipótese de que o nome do Grupo possa ser analisado como um "sintoma", uma expressão das relações entre a produção de legitimidade para a instituição e a ressignificação de Ouro Preto como cidade de memória. Para compreender melhor tais conexões é necessário fazer algumas considerações importantes sobre a história do município.

Criada a partir da fusão de dezesseis arraiais, ${ }^{34}$ que se organizaram, primeiramente, em uma vila e, depois, em cidade, Ouro Preto tornou-se capital da Capitania de Minas Gerais quando essa foi criada em 1720. Com o nome de Vila Rica, aquela localidade passou a constituir um centro de autoridade e vigilância em virtude da atividade mineradora. Foi nesse período que Vila Rica começou a construir uma imagem correspondente ao seu status de capital de uma Capitania independente e poderosa. A constituição dessa imagem parece ter envolvido, em especial, a construção de matrizes próprias, que substituíram as antigas capelas, além do adensamento e consolidação do povoamento. Mais tarde, entre os anos de 1735 e 1763, no governo de Gomes Freire de Andrade, novas e expressivas intervenções urbanas foram feitas. Ergueram-se pontes e chafarizes; o centro administrativo foi delimitado, com a construção do Palácio-Fortaleza; e, arruamentos foram revestidos.

O fato de a Capitania de Minas Gerais ser o lugar mais rico e populoso da colônia, na época, tinha como consequência investimentos por parte da coroa portuguesa para melhorar o local. Essa iniciativa expressava-se por meio da substituição de antigas construções por novas edificações, principalmente. Aliada a isso, a afirmação de poder e autonomia de grupos locais também ajudava a compor o quadro de importância de Vila Rica. Mas, o gradativo esgotamento das minas e as crescentes perseguições políticas posteriores à Inconfidência Mineira promoveram um progressivo movimento de dispersão da população.

32 Dado produzido a partir das informações obtidas no documento que contém uma cópia do inventário do Grupo Escolar D. Pedro II, datado de 2 de agosto de 1911. APM. SI 3811.

33 APM. SI 3382. Dados produzidos por meio do relatório anual a respeito do ano de 1913, da diretora do Grupo Escolar de Ouro Preto, Ubaldina Ferreira de Carvalho, para a Secretaria do Interior. 31 de dezembro de 1913. É preciso esclarecer que não foi possível constatar se o ato de 26 de novembro foi estadual ou municipal e nem reconstruir os detalhes de seu processo de elaboração.

34 De acordo com o estudo feito por Rodrigo Meniconi, os arraiais atendiam pelos nomes de Botafogo, Cabeças Caquende, Pilar, Paulistas, Antônio Dias, Encardideira, Alto da Cruz, Padre Faria, São Sebastião, Ouro Podre, Santana, São João, Piedade e Taquaral. MENICONI, Rodrigo Otávio de Marco. A construção de uma cidade-monumento. 
Entretanto, como explica Meniconi, "a decadência do ouro não significa a decadência da cidade; na verdade, a sua construção prossegue". ${ }^{35}$. O autor destaca que, em 1823, quando o título de Imperial Cidade foi concedido a Ouro Preto, essa localidade deixou de ser vila. Em 1830, a Câmara promulgou um conjunto de leis e normas com o objetivo de regular a cidade, determinando, inclusive, diretrizes para a realização de novas construções. Embora tais preceitos, talvez, nunca tivessem sido cumpridos na íntegra, foram importantes na medida em que marcaram o início de um processo de conservação da estrutura construída no passado.

Apesar das considerações feitas por Rodrigo Meniconi em sua pesquisa ressaltarem a constituição de uma posição de destaque para Vila Rica, no século XVIII, e, posteriormente, no século XIX, já como Ouro Preto, Caion Natal atenta para o fato de que, desde os setecentos, a região já vinha sendo acometida por estigmas e, no alvorar do século seguinte, já sofrendo com a queda das atividades mineradoras, Ouro Preto era vista como uma capital cuja imagem era de desordem, irracionalidade e decadência. Contudo, apesar daquela cidade ser representada por uma parte das autoridades políticas e intelectuais, como inadequada para ocupar o lugar de capital da província, ela foi escolhida, em fins do século XIX, ainda no regime imperial, para a criação de uma das instituições educacionais que teve importância decisiva na cena mineira: a Escola de Minas de Ouro Preto. Como já foi mencionado em outra seção deste artigo, aquela instituição foi um dos elementos fundamentais para a constituição de uma ordem para o regime imperial. Além de realizar um trabalho significativo no que concerne a educação, a Escola de Minas deixou sua marca na região.

De acordo com José Murilo de Carvalho, a criação da Escola foi obra da iniciativa de D. Pedro II. ${ }^{36}$ Apesar de o país em fins do século XIX ter uma economia essencialmente agrícola, exportadora e escravocrata e dificilmente precisar de geólogos e engenheiros, D. Pedro II parecia corroborar da opinião daqueles que desde 1823 já discutiam sobre a implantação de uma escola de minas na província de Minas Gerais como forma de resolver a decadência da atividade mineradora. Por isso, afirma Carvalho, a criação da Escola de Minas foi, antes de tudo, um ato político e ideológico e não econômico. A escolha de Ouro Preto como lugar estratégico para a implantação da instituição, em 1876, esteve relacionada à constituição mineralógica da região e ao fato de ser Ouro Preto a capital da província de Minas Gerais na época, concentrando a estrutura burocrática e o poder político provincial. Embora sua implantação e consolidação tenham enfrentado muitos problemas e resistências por parte de uma parcela da classe política da época, o fato de Ouro Preto sediar a Escola de Minas Ihe conferiu certa deferência

35 CARVALHO, Rosana Areal de; MÁRQUES, Elisângela F.; FARIA, Vinícius Leal. Grupo Escolar de Mariana.

36 CARVALHO, José Murilo de. A escola de Minas de Ouro Preto. 
e pelo fato da existência da instituição se dever em grande parte à iniciativa de D. Pedro II pode-se levantar a seguinte questão: o nome do Grupo Escolar de Ouro Preto poderia ser uma homenagem àquele que de certa forma contribuiu para projetar a cidade nacionalmente por meio da criação de uma das instituições educacionais mais importantes de Minas Gerais?

Com o advento da República, momento em que os ideais de progresso e modernização foram legitimados e reforçados, e mesmo com a criação da Escola de Minas, Ouro Preto, que já não desfrutava de um lugar econômico privilegiado, passou a ser considerada como símbolo da decadência da economia aurífera; como um núcleo colonial atrofiado, na medida em que suas ruas eram irregulares, estreitas, mal traçadas e não estavam de acordo com os preceitos modernos de circulação e fluência; era considerada uma cidade suja, ${ }^{37}$ insalubre e desprovida de um sistema de esgoto e água encanada eficiente. Outro aspecto negativo presente na imagem de Ouro Preto eram suas características topográficas. Seu terreno repleto de acidentes geográficos era mais um incômodo "no caminho para a civilização".

Os discursos em voga, nos anos finais do século XIX, representavam Ouro Preto como uma cidade instituída sob o signo do improviso e da desordem. Roger Chartier enfatiza que as representações do social não são neutras: "produzem estratégias e práticas (sociais, escolares, políticas) que tendem a impor uma autoridade a custa de outras, por elas menosprezadas, a legitimar um projecto reformador ou a justificar, para os próprios indivíduos, as suas escolhas e condutas". ${ }^{38}$ Em relação a Ouro Preto, o estigma de cidade colonial, que passou a ser símbolo do antigo regime imperial, que a acompanhava, gerava questionamentos acerca de sua condição para permanecer como capital de Minas Gerais. ${ }^{39}$ Aqueles que se posicionavam a favor da mudança acreditavam que a capital de Minas Gerais deveria ser uma cidade planejada, que simbolizasse o início de um processo civilizador. Cynthia Greive Veiga associa tal ideia à "expressão de uma nova concepção do social, do cultural e da importância da ciência que emerge em confronto com práticas tradicionais de se pensar a relação dos indivíduos com a cidade". ${ }^{40}$ Para os que defendiam a permanência de Ouro Preto como capital de Minas, bastava remodelar a cidade, apagando

37 Natal afirma que a questão da higiene foi motivo de muitas críticas dirigidas a Ouro Preto. Afinal, "as preocupações urbano-sanitárias foram recorrentes no século XIX, permearam as principais nações européias e constituíram um relevante problema social, uma barreira no caminho da civilização. Era preciso sanar as cidades doentes, atrofiadas e débeis, para promover o progresso de uma nação". NATAL, Caion Meneguello. Ouro Preto, p.25.

38 Ver: CHARTIER, Roger. A história cultural, p.17.

39 Na verdade, como mostram Cynthia Veiga e Caion Natal, a validade do status de Ouro Preto como capital já havia sido alvo de questionamentos desde o movimento da Inconfidência Mineira, que tinha como um de seus projetos mudar a capital para São João Del Rei. Essas propostas de mudança continuaram aparecendo ao longo do século XIX, como por exemplo, nos anos de 1833, 1834 e em 1851. VEIGA, Cynthia Greive. Cidadania e educação na trama da cidade: a construção de Belo Horizonte em fins do século XIX. Campinas: Universidade Estadual de Campinas, 1994 (Educação, Tese de doutorado); NATAL, Caion Meneguello. Ouro Preto.

40 VEIGA, Cynthia Greive. Cidadania e educação na trama da cidade, p.69. 
de sua materialidade as marcas que remontassem ao passado colonial e imperial, ressaltando o progresso sobre a imagem da tradição que a antiga Vila Rica expressava.

Apesar daqueles que se posicionavam contrariamente, em 1891, a mudança da capital para um local que possuísse condições higiênicas mais adequadas foi declarada. Foram indicadas algumas cidades candidatas à nova condição e estudos técnicos começaram a ser realizados para avaliar cada uma delas ${ }^{41}$ Meniconi indica que os seguintes aspectos deveriam ser considerados ao se fazer as análises:

O estabelecimento de uma cidade de 150 a 200 mil habitantes. Deveriam ser examinadas as condições naturais de salubridade, o abastecimento abundante de água potável, os esgotos e conveniente escoamento das águas pluviais, as facilidades oferecidas para a edificação e construção em geral, o farto abastecimento dos produtos da pequena lavoura indispensáveis ao consumo diário, a iluminação pública e particular, de forma a oferecer as condições de conforto requeridas pela via moderna, com a indicação do sistema preferível, as condições topográficas em relação à livre circulação de veículos e ao abastecimento de carris urbanos, a ligação ao plano geral da viação estadual e federal e, finalmente, a despesa mínima que as instalações iniciais, exigiriam com o custo das implantações, dos projetos a serem executados e da construção dos edifícios representativos. ${ }^{42}$

Todas essas condições eram pautadas por preceitos científicos e positivistas, além de interesses políticos e econômicos. Por ser considerada incapaz de atender a todas as exigências mencionadas, foi descartada a possibilidade de Ouro Preto se manter como capital de Minas Gerais. No entanto, no mesmo ano em que a mudança da sede administrativa foi decretada, foi criada, em Ouro Preto, a Empresa de Melhoramentos da Capital, por meio de um contrato firmado entre a Intendência Municipal ouropretana, Vicente Barreiros e Alexandre Moura Costa. O objetivo era tornar a localidade, símbolo do atraso e da inoperância, em uma cidade mais plana, higiênica, salubre, limpa, arborizada, organizada, alinhada. Enfim, desejava-se reinventar Ouro Preto, torná-la mais moderna. Mas, o contraste entre o projeto que se pretendia realizar e as condições concretas para fazê-lo logo se colocou como obstáculo. Sem poder contar com recursos do município, a Empresa de Melhoramentos recorreu ao governo estadual, que emprestou um montante insuficiente para a empreitada.

\footnotetext{
41 Natal lista as seguintes localidades: Juiz de Fora, Barbacena, Várzea do Marçal, Paraúna e Curral Del Rey (mais tarde, Belo Horizonte). A indicação dessas localidades como possíveis capitais de Minas relaciona-se aos interesses dos grupos de cafeicultores presentes na província mineira naquela época. A comissão responsável por fazer os estudos era chefiada pelo engenheiro Aarão Reis. Ver: NATAL, Caion Meneguello. Ouro Preto.

42 MENICONI, Rodrigo Otávio de Marco. A construção de uma cidade-monumento, p.60.
} 
Em 1892, foi publicado pela Câmara de Ouro Preto um edital que previa a incorporação de novos terrenos à cidade com o intuito de ampliá-la. ${ }^{43}$ No ano seguinte, a mesma instituição contratou os serviços do engenheiro João Blaksley para elaborar um projeto de construção da nova Ouro Preto, nos terrenos que foram anexados à cidade tempos antes. Aliado à ideia de reconstruir a antiga capital estava o discurso de conservação do antigo núcleo de Ouro Preto, representado como palco da luta em favor da liberdade de expressão e criação artística e contra a tirania. No projeto do engenheiro Blaksley também havia esse apelo à memória, porém as principais questões contempladas foram aquelas em consonância com os preceitos de modernidade, tais como abastecimento, salubridade, topografia e custo, aspectos funcionais de circulação, assemelhando-se às principais questões do trabalho de Aarão Reis.

Aqueles que defendiam a permanência de Ouro Preto como capital evocavam o panteão de figuras históricas importantes que lá viveram. A cidade era representada como a "guardiã" da tradição. ${ }^{44}$ Mas, nem mesmo todas as estratégias desenvolvidas foram suficientes para impedir que fosse aprovada, em 1893, a construção do novo centro administrativo e político de Minas Gerais no Curral Del Rey, posteriormente, Belo Horizonte. ${ }^{45}$ Meniconi afirma que, nos primeiros anos, sem a condição de capital do estado, Ouro Preto era o símbolo do abandono e do esquecimento. O autor explica que "a construção da nova capital e o êxodo que se seguiu - calcula-se que mais de $45 \%$ da população tenha emigrado - vão colocar Ouro Preto em uma espécie de limbo, um local fora do tempo". ${ }^{46}$

Além dos funcionários públicos que migraram para Belo Horizonte, comerciantes e profissionais liberais também foram em busca de regiões com melhores mercados. Em meio a esse contexto de crise econômica e problemas de gestão municipal, os discursos daqueles que não apoiaram a mudança da capital foram direcionados para o apelo à preservação e conservação da "histórica" cidade. Afinal, Ouro Preto seria um elemento constitutivo das identidades nacional e mineira. Os discursos que criticavam o esquecimento da cidade já vinham sendo propagados desde os fins do século XIX, em um movimento de exaltação da memória nacional, em que

43 A partir da Proclamação da República, as Câmaras Municipais foram restauradas. GONÇALVES NETO, Wenceslau. Capital e interior.

44 O marco desse movimento de defesa de Ouro Preto como o reduto da tradição foi a inauguração do monumento dedicado a Tiradentes, em que pode ser percebida a intenção de sacralizar não apenas a imagem do inconfidente, mas também a própria Vila Rica. MENICONI, Rodrigo Otávio de Marco. A construção de uma cidade-monumento; NATAL, Caion Meneguello. Ouro Preto.

45 Beatriz Magalhães e Rodrigo Andrade salientam que a mudança de nomenclatura sinalizou a busca por uma nova classificação do espaço. O novo horizonte que se pretendia produzir com a República, não apenas de forma simbólica, mas também espacial, começava a ser delineado concretamente, sugerindo uma nova ordem relativa, entre outros aspectos, à questão do espaço. MAGALHÃES, Beatriz de Almeida; ANDRADE, Rodrigo Ferreira. Belo Horizonte: um espaço para a República. Belo Horizonte: Editora UFMG, 1989.

46 MENICONI, Rodrigo Otávio de Marco. A construção de uma cidade-monumento, p.68. 
um dos marcos foi a criação do Arquivo Público Mineiro, em 1895, e o lançamento da sua revista, em 1896, e da obra Efemérides Mineiras, em 1897.

Durante os primeiros anos do século XX, o movimento que objetivava conferir a Ouro Preto o status de lugar único, singular, continuou crescendo. Em 1911, as comemorações do bicentenário da cidade, evento organizado pelo jornalista e escritor Nelson de Senna, reforçaram o processo de sua constituição como lugar de memória preservada. Durante as manifestações ocorridas no bicentenário, procurou-se estabelecer conexões históricas entre Ouro Preto e Belo Horizonte, de modo que a nova capital parecesse um prolongamento da antiga. Dessa maneira, Ouro Preto não seria mais renegada, esquecida, mas seria considerada o suporte moral de Belo Horizonte, a origem de sua modernidade. Portanto, buscava-se aliar um discurso progressista, em favor da nova e moderna capital, a um discurso de conservação e tradição, que tinha na antiga capital o seu centro.

Passado e futuro eram, então, vistos como a face de uma mesma moeda: enquanto Belo Horizonte representava o espírito empreendedor do mineiro, o desenvolvimento econômico, o progresso científico, Ouro Preto representava a raiz desse progresso, o nascedouro da identidade mineira. ${ }^{47}$

O anseio por parte daqueles que não aprovaram a mudança da sede administrativa do estado para Belo Horizonte de produzir para Ouro Preto a representação de lugar de memória preservada pode, como já sinalizamos anteriormente, ajudar a explicar porque foi conferido ao Grupo Escolar da cidade o nome de D. Pedro II. Em 1908, ano em que a instituição foi criada legalmente e que recebeu a denominação, o movimento de exaltação à história de Ouro Preto estava efervescendo, e inscrever naquela que poderia ser a principal escola de instrução primária pública do município o nome de um personagem que tem relação direta com essa história poderia ser um profícuo meio de conferir a ela visibilidade. Aliado a isso, e não menos importante, está também a questão da presença significativa do espírito monarquista entre os ouropretanos, nos tempos iniciais da República.

A criação dos grupos escolares seria uma forma, um meio de perpetuar e lançar luzes sobre a ação republicana. Nesse contexto, nomear aquelas instituições com nomes de homens que ocuparam cargos expressivos no regime republicano poderia constituir uma maneira de tornar "a República imortalizada na memória coletiva pela lembrança de seus representantes máximos". ${ }^{88}$ No caso de Ouro Preto, o que se percebe é, talvez, um desejo de se celebrizar um passado no qual e do qual a cidade foi símbolo. Assim, a escolha por não imortalizar a memória de um regime político no qual se

47 NATAL, Caion Meneguello. Ouro Preto, p.102.

48 SOUZA, Rosa Fátima de. Templos de civilização, p.134. 
concretizou sua perda de status talvez consistisse em uma estratégia, cujo objetivo seria eternizar o período em que Ouro Preto era a sede administrativa do estado, o centro do poder em Minas Gerais, o que contribuiria significativamente para alavancar seu processo de constituição de lugar de memória preservada.

Dessa forma, mais do que imortalizar a memória de um regime, o nome da instituição serviria de instrumento para eternizar a memória da cidade, processo observado por Luciano Faria Filho também em relação aos grupos escolares de Belo Horizonte que, a princípio, denominavam-se como Primeiro Grupo, Segundo Grupo e Terceiro Grupo, e algum tempo depois, passaram a receber nomes de personalidades. ${ }^{49}$ Esse fato está relacionado à ideia salientada por Cynthia Veiga sobre a indissociabilidade entre a cidade e a escola. Na perspectiva da autora, não se pode falar em uma situação em que há complementaridade entre o que se passa nos limites da esfera municipal e o que ocorre na escola. ${ }^{50}$ Essa integra a cidade e, por isso, vivencia os processos que lá se desenvolvem.

No caso de Ouro Preto, imprimir ao Grupo Escolar a nomenclatura de D. Pedro II poderia significar, ainda, uma homenagem àquele que talvez fosse visto como o benemérito da instituição, na medida em que o Grupo foi instalado em prédio doado à cidade pelo ex-imperador. Rosa Souza explica que o Estado republicano recorria à estratégia de denominar os grupos escolares com nomes daqueles que contribuíam financeiramente para a construção ou adaptação dos prédios destinados à instalação das instituições. Destarte, "em troca da doação financeira a homenagem eternizada". Por meio desse recurso, a figura do patrono era estabelecida. Figura que deveria ser exaltada pela comunidade escolar. ${ }^{51}$

Esse enaltecimento poderia ser percebido, por exemplo, pela exposição do retrato do patrono em algum lugar de notoriedade do grupo. No caso do Grupo de Ouro Preto, em 1917, quase 26 anos após a morte do último Imperador do Brasil, a então diretora da instituição enviou à Secretaria do Interior um ofício em que comunicava ter recebido um retrato de D. Pedro Il e que havia o desejo de colocá-lo "no salão nobre do vosso predio, no dia da inauguração do mesmo". ${ }^{52}$ A Secretaria do Interior parece ter não somente aprovado a ideia, como também parabenizado quem a concebeu. ${ }^{53}$

49 FARIA FILHO, Luciano Mendes de. Dos pardieiros aos palácios: cultura escolar e urbana em Belo Horizonte na Primeira República.

50 VEIGA, Cynthia Greive. Cidade, escola e urbanidade na elaboração da relação entre professor e alunos no início do século XX. In: GALVÃO, Ana Maria de Oliveira; LOPES, Eliane Marta Teixeira (orgs.). Boletim vida escolar: uma fonte e múltiplas leituras sobre a Educação no início do século XIX. Belo Horizonte: Autêntica, 2011, p.113-141.

51 SOUZA, Rosa Fátima de. Templos de civilização, p.134.

52 APM. SI 3667. Ofício enviado ao Secretário do Interior, Américo Ferreira Lopes, pela diretora do Grupo Escolar de Ouro Preto, Anna Ferreira Guimarães. 1 de outubro de 1917.

53 APM. SI 3667. Anotação feita pelos funcionários Turiano Pereira e F. Mattos, da 6 a secção da Secretaria do Interior no ofício enviado pela diretora Anna Ferreira Guimarães ao Secretário do Interior, em 1 de outubro de 1917. 3 de outubro de 1917. 
O retrato não era, somente, um mero objeto decorativo do interior do grupo. A imagem do patrono, além de homenagear um determinado personagem, funcionaria como um meio de legitimar a história social e política do lugar em que o grupo estava instalado, e também como uma forma de engendrar uma memória responsável por relacionar a história da instituição com a história social. Se no caso de outros grupos escolares a imagem do patrono ratificava a República e servia como pretexto para exaltá-la como o regime que ofereceu à população brasileira a escola de verdade, em Ouro Preto o que, aparentemente, se pretendia evocar, por meio do nome do Grupo Escolar, era uma história que evidenciava a posição de destaque que, outrora, o município ocupava. É possível que a exposição do retrato no interior da instituição não fosse apenas uma homenagem, mas também que simbolizasse a tradição que a cidade desejava manter.

\section{Apontamentos finais}

O processo de criação dos grupos escolares em diferentes regiões do Brasil, inclusive em Minas Gerais, foi marcado por discursos elaborados por agentes políticos e por uma legislação que sugeriram a ideia de que aquelas instituições surgiram imbuídas de legitimidade, concepção que foi endossada, de modo geral, pela historiografia. Todavia, o que pudemos constatar foi que precisou ser forjado, para o grupo escolar, um lugar legítimo que não era inerente a ele. A construção daquele lugar se deu por meio de uma trama tecida gradativamente e composta por diversos elementos. $\mathrm{O}$ contexto do qual o grupo escolar fazia parte parece ter desempenhado papel fundamental em seu processo de legitimação como instituição de saber. Em outras palavras, a história dos locais onde os grupos foram implantados parece ter influenciado na produção de sua legitimidade.

Neste artigo, objetivamos discutir como a história de Ouro Preto, delineada ao longo dos anos, a situação de decadência em que a cidade se encontrava em fins do século XIX e início do século XX e sua constituição como lugar de memória preservada, "histórico", pode ter influído na construção de uma representação legítima para o Grupo Escolar D. Pedro II. As discussões a respeito da criação da instituição em Ouro Preto datam de 1907, poucos meses após a promulgação da Lei n. 439, que criou oficialmente os grupos escolares em Minas Gerais. A ocasião dos primeiros debates acerca da fundação de um grupo escolar na antiga capital do estado foi marcada, aparentemente, por certa resistência em relação à implantação da instituição. Alguns obstáculos, como a escassez de recursos e a falta de um prédio adequado, foram alegados como dificuldades para concretizar a proposta.

Entretanto, apesar de parecerem reais, havia um entrave que poderia ser maior do que aqueles que, num primeiro momento, foram mencionados: 
uma possível oposição de uma parte dos agentes políticos de Ouro Preto em relação à criação do Grupo Escolar. Mas, o que a teria motivado? Os elos entre a antiga Vila Rica e o regime imperial poderiam ser a explicação. Na verdade, mais do que a ligação da cidade com o Império, mas sim a frustração gerada pela perda de status e prestígio causada pela transferência da sede administrativa do estado para Belo Horizonte, nos tempos iniciais da República. Ao ser destituída do posto de capital de Minas Gerais, Ouro Preto não perdeu apenas sua posição política no estado, perdeu também uma parte da população e mergulhou em um estado de decadência.

A despeito das resistências iniciais, o Grupo Escolar ouropretano foi criado e denominado de D. Pedro II, uma referência ao doador do prédio onde a escola foi instalada e ao passado da cidade, cujo processo de exaltação que foi sendo construído ao longo dos anos foi o responsável por conferir relevância novamente a Ouro Preto. O fato de o Grupo Escolar daquele município ter recebido a designação do último regente do Império vai na contramão da história de grande parte dos grupos escolares brasileiros que recebiam nomes de personalidades da cena republicana. No caso do Grupo D. Pedro II, mais do que exaltar um regime, o nome da instituição era um tributo à própria cidade. A história de Ouro Preto, portanto, é um dos elementos que contribuiu para a construção e representação cotidianas do Grupo Escolar. 